\title{
ANALISIS TERJEMAHAN EUFEMISME ORGAN DAN AKTIFITAS SEKSUAL DALAM NOVEL FIFTY SHADES OF GREY
}

\author{
Desi Zauhana Arifin ${ }^{1}$, Djatmika ${ }^{2}$, Tri Wiratno ${ }^{3}$ \\ ${ }^{1}$ Magister Linguistik Penerjemahan Pascasarjana Universitas Sebelas Maret \\ ${ }^{2,3}$ Universitas Sebelas Maret, Surakarta, Indonesia \\ 1dezauhana@gmail.com; ${ }^{2}$ djatmika@staff.uns.ac.id; ${ }^{3}$ tri_wiratno@staff.uns.ac.id
}

\begin{abstract}
This research is aimed to: (1) identify the kinds of euphemism sexual organ and sexual activity in Fifty Shades of Grey novel, (2) identify the translation techniques used by the translator in translating sexual organ and sexual activity with euphemism, (3) describe the impact of translation technique which applied by the translator toward translation quality in terms of accuracy and acceptability. This research is a descriptive-qualitative research. Sources of data are Fifty Shades of Grey novel also informans who assess the quality of the translation. Data were collected by using document analysis, questionnaires, and focus group discussion (FGD). Data were analyzed by using Spradley's ethnography method. The result of this research shows that there are 10 kinds of euphemism in sexual organ and sexual activity in Fifty Shades of Grey novel. The most dominating euphemism sexual organ of this data is general for specific with the percentation as many as $47.14 \%$, while in sexual activity, the most dominating euphemism is hyperbole with percentation $29.37 \%$. In this research there are thirteen techniques which used by the translator to translate sexual organ and sexual activity with euphemism, the technique which dominates is established equivalent with the percentation $47.43 \%$. For the translation quality, 117 data (59,7\%) were accurately translated, 66 data (33,7\%) were less accurately translated 13 data $(6,6 \%)$ were not accurately translated and there were 112 data $(57,1 \%)$ identified as acceptable translation, 74 data $(37,8 \%)$ are less acceptable translation, and 10 data $(5,1 \%)$ are not acceptable translation. The conclusion of this research shows that lots of euphemisms were found in Fifty Shades of Grey novel and some of translation techniques have negative impact towards the translation quality of Fifty Shades of Grey novel. This research only uses euphemism sexual organ and sexual activity in Fifty Shades of Grey novel. The other reference of euphemism can be used as the data for further research.
\end{abstract}

Keywords: Euphemism, translation techniques, translation quality

\section{PENDAHULUAN}

Di dalam kajian semantik, eufemisme termasuk ke dalam perubahan makna. Dalam pendapatnya, Chaer (1994:144) mengatakan bahwa eufemisme adalah gejala ditampilkannya kata-kata atau bentuk-bentuk yang dianggap memiliki makna yang lebih halus, atau lebih sopan daripada yang akan digantikan. 
Didalam pendapatnya, Chaer (1989:60) menyatakan bahwa dalam semantik yang dibicarakan adalah hubungan antara kata dengan konsep atau makna dari kata tersebut, serta benda atau hal-hal yang dirujuk oleh makna itu yang berada diluar bahasa. Makna dari sebuah kata, ungkapan atau wacana ditentukan oleh konteks yang ada.

Selain eufemisme yang merupakan bagian dari perubahan makna, ada juga beberapa istilah lain yang juga merupakan bagian dari perubahan makna yaitu makna amelioratif dan peyoratif. Kata-kata yang nilainya menjadi rendah disebut dengan istilah peyoratif, sedangkan yang nilainya menjadi tinggi disebut dengan amelioratif. Misalnya kata istri dianggap amelioratif dari kata "bini" yang dianggap peyoratif. Penggunaan eufemisme pada kata tersebut adalah menghindari kesan kasar dan kurang berterima bagi beberapa orang. Eufemisme mampu mengemas segala sesuatu yang dianggap tidak baik sehingga menjadi baik. Eufemisme juga berperan sebagai penetral makna.

Eufemisme sangat berkaitan dengan hal - hal yang tabu baik perbuatan maupun kata kata. Maka dari itu eufemisme sangat diperlukan untuk memperhalus kata kata yang tabu dan vulgar tersebut. Penerjemah juga harus memperhatikan pembaca sasaran yang akan membaca terjemahan tersebut, seperti yang diungkapkan oleh (Nababan, 2003:22) yaitu penerjemah harus jeli dan paham kepada budaya siapa teks tersebut diperuntukkan.

Eufemisme banyak terdapat di dalam teks untuk membuat teks lebih berterima dengan kata-kata yang lebih halus. Dalam berkomunikasi, pada umumnya manusia juga menggunakan bahasa yang sopan dan santun untuk menghormati lawan bicara. Kenyataannya, penghalusan sangat diperlukan guna mengurangi kesalahpahaman atau ketersinggungan antara pembicara dan pendengar. Penghalusan juga digunakan untuk membuat kata kata yang terkesan vulgar menjadi lebih halus untuk didengar walaupun makna yang diterima akan sama. Maka dari itu peneliti tertarik untuk mengkaji eufemisme yang terdapat dalam novel.

Novel merupakan karya yang di dalamnya menggunakan bahasa yang indah. Dalam novel dewasa sering sekali kita jumpai penghalusan dari kata yang memiliki makna vulgar dan tabu yang dapat mempengaruhi keberterimaan sebuah novel. Penghalusan juga sering terjadi pada terjemahan novel terutama pada novel dewasa terkait dengan budaya yang ada. Pada penelitian ini, peneliti memilih novel Fifty Shades 
of Grey (2011) dan terjemahannya. Ada beberapa hal yang membuat peneliti tertarik untuk mengkaji eufemisme di dalam novel tersebut. Yang pertama, novel Fifty Shades of Grey merupakan novel dewasa yang terjual lebih dari 100 juta copy. Hal ini membuktikan bahwa novel ini sangat menarik minat pembaca. Di dalam Novel ini terdapat aktifitas seksual dan organ seksual. Setelah membaca keseluruhan isi novel Fifty Shades of Grey dan terjemahannya, peneliti menemukan bahwa di dalam novel tersebut terdapat banyak bentuk eufemisme yang menarik untuk dikaji secara mendalam. Hal ini disebabkan eufemisme memang sering kita jumpai pada novel dewasa, majalah dewasa, artikel politik dan lain lain.

Berdasarkan pembahasan pada latar belakang masalah dan Penelitianpenelitian yang telah dilakukan oleh beberapa peneliti sebelumnya terdapat sejumlah masalah yang dapat diteliti lebih mendalam dan dikembangkan. Sebagian besar peneliti terdahulu mengkaji eufemisme yang terdapat pada bahasa daerah dan juga wacana yang berbau politik. Meskipun beberapa penelitian sebelumnya sudah membahas secara detail bentuk eufemisme serta makna dan kaitannya dengan budaya, namun dari keseluruhan penelitian belum ada yang mengacu pada produk terjemahan sebuah film ataupun novel. maka dapat dihasilkan beberapa tujuan penelitan yaitu; pertama, Untuk mengidentifikasi bentuk eufemisme organ dan aktifitas seksual dalam novel Fifty Shades of Grey. Untuk mengidentifikasi teknik penerjemahan yang digunakan pada eufemisme organ dan aktifitas seksual dalam novel Fifty Shades of Grey. Ketiga, untuk mendeskripsikan dampak dari teknik yang digunakan penerjemah terhadap kualitas terjemahan dari segi keakuratan dan keberterimaan pada eufemisme organ dan aktifitas seksual dalam novel Fifty Shades of Grey.

\section{TEORI DAN METODOLOGI}

Pada penelitian ini, peneliti akan menggunakan teori Molina dan Albir yang akan digunakan untuk menganalisis teknik penerjemahan yang dilakukan penerjemah dalam menerjemahkan kalimat yang mengandung eufemisme dalam novel Fifty Shades of Grey. Teknik-teknik tersebut antara lain meliputi;

1. Teknik Kesepadanan Lazim: Fungsi kesepadanan lazim merupakan teknik penggunaan istilah atau ungkapan yang telah lazim digunakan, diakui dalam kamus atau bahasa sasaran sebagai padanan dari Bsu tersebut 
2. Teknik Kompresi Linguistik: Teknik ini merupakan teknik mensintesis elemen linguistik yang ada menjadi lebih sederhana karena sudah dapat dipahami.

3. Teknik peminjaman: Teknik borrowing merupakan teknik peminjaman langsung suatu kata atau ungkapan dari bahasa lain.

4. Teknik Modulasi: Modulasi merupakan teknik penggantian sudut pandang, fokus atau kategori kognitif dari Bsa; bisa dalam bentuk struktural maupun leksikal.

5. Teknik Kompensasi: Kompensasi merupakan teknik yang memperkenalkan elemen informasi atau efek stilistik pada tempat lain pada Bsa karena tidak ditempatkan pada posisi yang sama seperti dalam Bsu.

6. Teknik Reduksi: Teknik ini adalah teknik yang mengimplisitkan informasi karena komponen maknanya sudah termasuk dalam bahasa sasaran.

7. Teknik Amplifikasi: Amplifikasi merupakn teknik yang memperkenalkan informasi secara detail atau mengeksplisitkan informasi yang tidak terurai dalam Bsu

8. Teknik Adaptasi: Adaptasi merupakan teknik penggantian elemen budaya pada Bsu dengan elemen yang bersifat sama pada budaya Bsa.

9. Teknik Amplifikasi Linguistik: Teknik ini merupakan teknik penambahan elemen linguistik sehingga terjemahannya lebih panjang.

10. Teknik transposisi: Transposisi merupakan teknik penggantian kategori grammar, misal dari verb menjadi adverb dan lain sebagainya.

11. Teknik Generalisasi: Generalisasi merupakan teknik penggunaan istilah yang lebih umum atau netral dalam bahasa sasaran

12. Teknik Variasi: Teknik variasi merupakan teknik penggantian unsur linguistik atau paralinguistic (intonasi, gestur) yang mempengaruhi aspek keragaman linguistik

13. Teknik Partikulasi: Partikularisasi merupakan teknik penggunaan istilah yang lebih spesifik dan konkrit bukan bentuk umumnya.

14. Teknik Kreasi Diskursif: Kreasi diskursif merupakan teknikpenggunaan suatu padanan temporer yang diluar konteks atau tak terprediksikan.

15. Teknik Kalke: Kalke merupakan teknik penerjemahan dengan mentransfer kata atau frasa dari Bsu secara harfiah ke Bsa baik secara leksikal maupun struktural. 
16. Teknik Deskripsi: Deskripsi yaitu mengganti sebuah istilah atau ungkapan dengan deskripsi bentuk atau fungsinya.

17. Teknik Harfiah: Teknik penerjemahan harfiah merupakan teknik penerjemahan suatu kata atau ungkapan secara kata perkata

18. Teknik Subtitusi: Teknik substitusi merupakan teknik penggantian elemen elemen linguistik dengan paralinguistik (intonasi, gesture) dan juga sebaliknya.

Menurut Nababan (2003: 86), penelitian terhadap mutu terjemahan terfokus pada tiga hal pokok yaitu: 1) ketepatan pengalihan pesan, ketepatan pengungkapan pesan dalam bahasa sasaran, dan 3) kealamiahan bahasa sasaran. Dalam penilaian kualitas terjemahan terdapat tiga komponen yang harus diperhatikan, yaitu keakuratan (accuracy), Keakuratan merupakan tepat atau tidaknya pengalihan pesan atau informasi yang disampaikan dari bahasa sumber kedalam bahasa sasaran. Komponen berikutnya adalah keberterimaan(acceptability), Keberterimaan merupakan sesuai atau tidaknya bahasa yang digunakan oleh penerjemah dalam menerjemahkan. Penerjemah harus menerjemahkan teks sesuai dengan tata bahasa dan kaidah yang berlaku pada bahasa sasaran. Keberterimaan suatu teks tidak hanya dilihat dari segi tata bahasanya saja namun harus memperhatikan budaya pada pembaca sasaran juga dan komponen yang terakhir adalah keterbacaan (readability). Suatu terjemahan dapat dikatakan memiliki tingkat keterbacaan yang baik apabila teks terjemahan tersebut mampu menyampaikan pesan yang terkandung dalam teks Bahasa sumber kedalam teks bahasa sasaran dengan baik. Keterbacaan berkaitan dengan mudah atau tidak bahasa tersebut untuk dipahami oleh pembaca sasaran. Ketiga aspek ini sangat penting bagi penerjemah untuk dijadikan pedoman agar menghasilkan kualitas terjemahan yang baik.

Untuk teori eufemisme diambil dari teori Menurut Allan dan Burridge (1991) teori yang dikemukakan oleh Allan dan Burridge (1991) membahas teori eufemisme lebih rinci. Allan dan Burridge (1991) membagi eufemisme menjadi beberapa bentuk antara lain :

1. Hyperbole: ungkapan yang melebih lebihkan

2. Figurative expression : bersifat perlambangan, ibarat atau kiasan.

3. Understatement: satu makna kata yang terlepas dari makna kata tersebut.

4. Flippancy : makna di luar pernyataan

5. Jargon : kata yang memiliki makna kata yang sama tetapi berbeda bentuk. 
6. Circumlocution : penggunaan beberapa kata yang lebih panjang dan bersifat tidak langsung.

7. Metaphor : perbandingan yang implisit di atara dua hal yang berbeda.

8. General for specific : kata yang umum menjadi kata yang khusus.

9. Part for whole euphemism : menghilangkan sebagian kecil.

10. Remodelling : satu kata untuk menggantikan satu kata yang lain.

11. Clipping : pemotongan, membuat menjadi pendek atau singkat.

12. Acronym : penyingkatan atas beberapa kata menjadi satu.

13. Abbreviation : singkatan kata kata menjadi beberapa huruf.

14. Omission : menghilangkan sebagian kecil

15. Colloquial: ungkapan yang sering dipakai.

16. One for one substitution : satu kata untuk menggantikan kata yang lain.

Penelitian ini adalah penelitian deskriptif kualitatif. Sasaran penelitian ini merupakan kalimat yang mengandung eufemisme yang terdapat pada novel Fifty Shades of Grey. Dalam penelitian ini, peneliti juga akan mendeskripsikan teknik apa saja yang digunakan oleh penerjemah dalam menerjemahkan dan bagaimana dampaknya terhadap kualitas hasil terjemahan itu sendiri.

Penelitian ini juga bersifat kualitatif karena data data tidak hanya dikumpulkan dan disusun namun juga dianalisis dan diinterpretasikan untuk kemudian ditarik kesimpulan (Soejono dan Abdurrahman, 1999: 22). Data yang dikumpulkan berupa kalimat yang mengandung eufemisme.

Pada penelitian deskriptif kualitatif ini data yang telah dikumpulkan akan dianalisis dan akan dijabarkan secara lengkap terbuka dan benar. Data data yang dikumpulkan berupa kalimat demi kalimat dan akan dijelaskan menggunakan tabel dan tabel akan dideskripsikan secara detail.

Penelitian ini bukan berorientasi pada proses melainkan pada produk terjemahan atau dengan kata lain terfokus pada karya terjemahan. Satuan terjemahan yang digunakan dalam bentuk kalimat tersebut nantinya akan digunakan sebagai dasar penentuan teknik yang dipakai dalam menerjemahkan eufemisme organ dan aktifitas seksual.

Dalam penelitian ini, peneliti akan menggunakan studi kasus terpancang (embedded-case study). Penelitian telah menentukan pokok permasalahan dan fokus 
penelitian seperti yang sudah dijelaskan pada rumusan masalah yaitu mengenai analisis eufemisme pada organ dan aktifitas seksual, teknik apa saja yang digunakan dalam menerjemahkan serta bagaimana dampaknya terhadap kualitas terjemahan.

Di dalam penelitian ini, peneliti menggunakan metode dengan membagikan kuesioner dan melakukan focus group discussion (FGD) dengan para informan (rater). Penelitian dengan pendekatan etnografi menuntut peneliti untuk melakukan penelitiannya terjun langsung di lokasi penelitian, yang bisa juga disebut sebagai studi lapangan. Dengan demikian data yang dihasilkan akan dterima keabsahannya.

Lokasi penelitian ini berupa novel yang berjudul Fifty Shade of Grey beserta terjemahannya. Novelnya yang sudah terjual lebih dari 100 juta kopi dan diterjemahkan ke dalam 30 bahasa aktor atau partisipannya adalah para tokoh dalam novel ini, dan peristiwanya berupa organ dan aktifitas seksual.

Teknik cuplikan dilakukan pada pemilihan novel Fifty Shades of Grey (2011) karya EL James sebagai sumber data yang cukup mengenai eufemisme pada organ dan aktifitas seksual. Teknik ini digunakan sebagai dasar pemilihan rater yang akan menilai kualitas terjemahan pada datayang diteliti baik aspek keakuratan maupun keberterimaan. Di dalam penelitian ini akan ada tiga rater yang dipilih berdasarkan kriteria tertentuse.

Dalam sebuah peneliatian terdapat data dan sumber data. Sutopo (2006: 56-61) menyatakan bahwa sumber data dalam penelitian kualitatif dapat berupa narasumber (informan), dokumen, peristiwa atau aktivitas, tempat atau lokasi, benda. Beragam gambar dan rekaman. Sumber data dalam penelitian ini mencakupi:

Pada penelitian ini menggunakan dua jenis sumber data, yakni dokumen dan informan. Dokumen dalam penelitian ini adalah novel yang berjudul Fifty Shades of Grey dan terjemahannya. Sumber data yang kedua adalah informan. Data yang dikaji dalam penelitian ini terdiri dari dua jenis yaitu data primer dan data sekunder.Data primer adalah organ dan aktifitas seksual yang mengandung eufemisme pada novel yang berjudul Fifty Shades of Grey terjemahannya, juga hasil dari kuesioner sekaligus focus group discussion dengan para rater mengenai keakuratan dan keberterimaan. Data sekunder yang digunakan oleh peneliti adalah informasi mengenai novel Fifty Shades of Grey dan beberapa penelitian sebelumnya yang membahas eufemisme. 
Teknik pengumpulan data yang akan digunakan dalam penelitian ini adalah teknik analisis dokumen (content analysis) Menurut sutopo (2006: 81) menyatakan bahwa teknik ini merupakan cara untuk menentukan beragam hal sesuai dengan kebutuhan dan tujuan penelitiannya. , kuesioner (questionaire) Sutopo (2006: 81) menyatakan bahwa kuesioner merupakan daftar pertanyaan untuk pengumpulan data dalam penelitian yang dapat dilakukan secara lisan dan tertulis. dalam penelitian ini peneliti membuat kuesioner secara tertulis yang akan diberikan kepada informan sebagai responden. Teknik ini digunakan untuk mengumpulkan data mengenai kualitas terjemahan yang dalam hal ini hanya akan dilihat pada point keakuratan dan keberterimaan terhadap kalimat-kalimat yang mengandung eufemisme pada novelFifty Shades of Grey. Data tersebut akan diperoleh dari ketiga rater yang telah ditentukan sehingga penilaian tentang kualitas yang mencakup dua poin diatas dapat lebih obyektif. Informasi yang didapat dari kuesioner tersebut selanjutnya akan dijadikan acuan dalam wawancara untuk memperoleh informasi lebih mendalam.

Kuesioner pada penelitian ini bersifat open and close yang berarti kuesioner pertama digunakan peneliti untuk mengukur tingkat keakuratan, kemudian kuesioner kedua digunakan untuk mengukur tingkat keberterimaan. Kedua kuesioner tersebut meliputi pertanyaan terbuka dan pertanyaan tertutup. Kedua point diatas menunjukkan skala penilaian.

Teknik berikutnya adalah FGD. FGD digunakan untuk menggali data tentang kualitas terjemahan secara mendalam dilakukan untuk memperoleh kemantapan. Diskusi ini bersifat lentur dan terbuka, tidak berstruktur ketat, tidak dalam suasana formal, dan bisa dilakukan berulang-ulang pada informan yang sama Sutopo (2006) Seperti disebutkan diatas bahwa hasil FGD ini merupakan penentu data yang dikumpulkan menggunakan teknik kuesioner. FGD dilakukan oleh ketiga rater untuk mendiskusikan kualitas terjemahan kalimat yang mengandung eufemisme. FGD dilakukan setelah kuesioner diserahkan kemudian didiskusikan secara bersama-sama.

Dalam menganalisis data, peneliti menggunakan empat teknik analisis data yang diadaptasi dari Spradley (1980). Keempat teknik analisis data tersebut, yaitu: analisis domain. Pada Tahapan analisis domain, data dipilah-pilahdengan teliti mana yang merupakan data dan mana yang bukan data. Data yang berupa organ dan aktifitas 
seksual yang mengandung eufemisme dikumpulkandari sumber data yang berupa novel Fifty Shades of Grey menggunakan pendekatan semantik. Dalam penelitian ini peneliti melakukan penilaian terhadap mana yang merupakan data dan mana yang bukan merupakan data. Pada tahap ini analisis domain bertujuan untuk menjadikan penelitian lebih terfokus. Analisis taksonomi, Analisis taksonomi merupakan analisis yang dilakukan dengan mengelompokkan semua data yang telah terkumpul berdasarkan pendekatan yang digunakan, yang dalam hal ini data yang dianalisis merupakan kalimat yang mengandung eufemisme. Analisis komponensial, Langkah ini dilakukan dengan melihat hubungan antara klasifikasi dan fenomena, yaitu menjawab pertanyaan penelitian seperti bagaimana dampak dari teknik, yang digunakan oleh penerjemah dalam menerjemahkan organ dan aktifitas seksual yang mengandung eufemisme. Kemudian bagaimana pengaruhnya terhadap kualitas terjemahan yang terdiri dari dua aspek yaitu aspek keakuratan dan keberterimaan. Yang terakhir adalah analisis tema budaya, Tahap ini adalah menggabungkan semua analisis seperti analisis domain, analisis taxonomi, analisis komponensial, hasil kuesioner dan hasil wawancara mendalam dan menempatkan mereka dalam seluruh konteks termasuk juga mempertimbangkan informasi data sekunder untuk menemukan latar belakang hasil penelitian. Dalam tahap ini kita akan dapat melihat bagaimana pengaruh teknik yang digunakan oleh penerjemah dalam menerjemahkan organ dan aktifitas seksual yang mengandung eufemismepada novel Fifty Shades of Grey dapat mempengaruhi tingkat keakuratan dan keberterimaan.

\section{HASIL DAN PEMBAHASAN}

\section{Bentuk- Bentuk Eufemisme}

Dari dua jenis eufemisme yaitu organ dan aktifitas seksual, ditemukan sejumlah 196 data. Data dalam kriteria sexual organ berjumlah 70 data dan data yang berupa sexual activity berjumlah 126 data. Berdasarkan bentuknya Allan dan Burridge (1991) membagi eufemisme menjadi 16 bentuk eufemisme dibagi menjadi 16 bentuk eufemisme, pada novel Fifty Shades of Grey dan terjemahannya dapat ditemukan 10 bentuk eufemisme antara lain Hyperbole sebanyak 37 data (18,9\%), general for specific sebanyak 33 data (16,8\%), figurative exxpression sebanyak 31 data (15,8\%), circumlocution sebanyak 31 data (15,2\%), jargon sebanyak 22 data (11,2\%), 
understatement sebanyak 16 data (8,2\%), flippancy sebanyak 14 data $(7,1 \%)$, metaphor sebanyak 7 data (3,6\%), colloquial sebanyak 5 data (2,5\%), dan part for whole euphemism 1 data( $0,5 \%)$.

Di bawah ini merupakan persentase eufemisme yang ditemukan pada novel Fifty Shades of Grey.

Tabel 1. Temuan Eufemisme Sexual organ dan Sexual Actifity

\begin{tabular}{rlcc}
\hline No & $\begin{array}{l}\text { Eufemisme dalam sexual } \\
\text { organ dan sexual activity }\end{array}$ & Jumlah & Persentase \\
\hline 1. & sexual organ. & 70 & 35,7 \\
\hline 2. & sexual activity & 126 & 64,3 \\
\hline Total & & 196 & 100 \\
\hline
\end{tabular}

Berdasarkan tabel di atas dapat kita lihat bahwa eufemisme organ dan aktifitas seksual banyak terdapat pada novel Fifty Shades of Grey. Novel ini merupakan novel dewasa yang menceritakan tentang hubungan intim tokoh dalam novel tersebut, sehingga banyak sekali penggunaan eufemisme untuk organ sexual. Dalam sexual activity juga banyak dijumpai penggunaan eufemisme dalam bentuk beberapa gaya bahasa, hal itu membuat kalimat-kalimat tersebut tidak terkesan terlalu vulgar. Serta dapat mengimplisitkan makna yang sebenarnya.

Pada Sexual organ, dari 10 bentuk eufemisme yang ditemukan dalam novel Fifty Shades of Grey, ditemukan 6 bentuk eufemisme pada sexual organ antara lain general for specific sebanyak 33 data $(47,1 \%)$, understatement sebanyak 16 data $(22,9 \%)$ flippancy 12 data (17,1\%), circumlocution sebanyak 7 data (10\%), metaphor sebanyak 1 data $(1,4 \%)$ dan part for whole euphemism sebanyak 1 data $(1,4 \%)$. eufemisme dalam sexual organ didominasi oleh bentuk general for specific. Penggunaan general for specific tersebut mendominasi karena novel Fifty Shades of Grey merupakan novel dewasa yang menceritakan tentang hubungan sexual yang tidak normal sehingga untuk mengungkapkan organ - organ sexual penulis menggunakan ungkapan yang umum untuk menunjukkan sesuatu yg khusus agar bersifat tidak langsung. 
Di dalam novel Fifty Shades of Grey, pada kategori sexual activity ditemukan sebanyak 126 data dari 10 bentuk eufemisme ditemukan 7 bentuk eufemisme antara lain Hyperbole sebanyak 37 data (29,4\%), figurative expression sebanyak 31 data (24,6\%), circumlocution sebanyak 23 data (18,5\%), jargon sebanyak 22 data (17,5\%), metaphor sebanyak 6 data (4,8\%), colloquial sebanyak 5 data (4,0\%), dan flippancy sebanyak 2 data (1,6\%). Eufemisme dalam bentuk hiperbola mendominasi pada sexual activity. Hal ini karena penulis menyajikan aktifitas - aktifitas sexual dengan menggunakan beberapa gaya bahasa antara lain hiperbola. Penggunaan gaya bahasa tersebut membuat kalimat kalimat tersebut terlihat gamblang dan detail dalam memaparkan aktifitas seksual dalam novel tersebut. Sehingga meskipun isi kalimat tersebut mengandung aktifitas sekual, kalimat kalimat tersebut berterima karena disajikan dalam bahasa yang baik.

Teknik penerjemahan menurut Molina dan Albir (2002:509) merupakan prosedur untuk menganalisis dan mengklasifikasikan bagaimana kesepadanan terjemahan berlangsung dan dapat diterapkan pada berbagai satuan lingual. Dalam hal ini dilakukan analisis teknik penerjemahan pada kalimat yang mengandung eufemisme. Dari 196 data yang dianalisis, ditemukan bahwa terjemahan kalimat yang mengandung eufemisnme dalam novel Fifty Shades of Grey karya EL James menggunakan 13 jenis teknik penerjemahan. Dari ke 13 teknik tersebut ditemukan sebanyak 799 teknik penerjemahan pada data yang telah dianalisis. Teknik yang ditemukan lebih dari jumlah data yang ada, hal ini karena data yang ditemukan sangat bervariatif, data yang ditemukan berupa kata, frasa, klausa, maupun kalimat sehingga teknik yang digunakan sangat banyak meskipun dalam satu data. Penggunaan teknik penerjemahan dapat dilihat secara rinci pada tabel berikut.

Tabel 2. Temuan Jenis Teknik Penerjemahan Eufemisme Organ dan Aktifitas Seksual Pada novel Fifty Shades of Grey

\begin{tabular}{rlll}
\hline No & Teknik penerjemahan & Jumlah & Presentase \\
\hline 1. & Kesepadanan lazim & 379 & 47,4 \\
\hline 2. & Amplifikasi & 120 & 15,2 \\
\hline 3. & Transposisi & 95 & 12,0 \\
\hline 4. & Reduksi & 93 & 11,6 \\
\hline 5. & Variasi & 53 & 6,6 \\
\hline 6. & Generalisasi & 14 & 1,7 \\
\hline 7. & Harfiah & 12 & 1,5
\end{tabular}




\begin{tabular}{clll}
\hline 8. & Kompensasi & 11 & 1,4 \\
\hline 9. & Kreasi diskursif & 9 & 1,1 \\
\hline 10 Adaptasi & 5 & 0,6 \\
\hline 11 Kompresi linguistik & 4 & 0,5 \\
\hline 12 Peminjaman & 3 & 0,4 \\
\hline 13 Modulasi & 1 & 0,1 \\
\hline Total & 799 & 100 \\
\hline
\end{tabular}

\section{Kualitas Terjemahan Kalimat yang Mengandung Eufemisme dalam novel Fifty Shades of Grey}

Dari 196 data yang telah dianalisis, kualitas terjemahan organ dan aktifitas seksual yang mengandung eufemisme pada novel Fifty Shades of Grey cenderung memiliki kualitas yang kurang baik. Meskipun begitu, terjemahan akurat masih mendominasi pada hasil penelitian ini dibandingkan data yang kurang akurat dan tidak akurat. Begitu juga dengan tingkat keberterimaan, meskipun tidak terlalu tinggi namun terjemahan yang berterima lebih mendominasi dibandingkan terjemahan yang kurang dan tidak berterima. Tingkat keakuratan pada terjemahan novel Fifty Shades of Grey cenderung cukup tinggi yaitu 59,7 \% dan keberterimaan 57,1\%. Dilihat dari persentase tersebut dapat disimpulkan bahwa penerapan teknik cenderung kurang baik terhadap kualitas terjemahan kalimat yang mengandung eufemisme pada novel Fifty Shades of Grey. Berdasarkan frekuensi penggunaan teknik penerjemahan, teknik kesepadanan lazim, amplifikasi dan transposisi mendominasi penelitian ini. Ketiga teknik ini cenderung memberikan nilai positif pada kualitas terjemahan. Namun penggunaan teknik reduksi dan kreasi diskursif juga cukup banyak sehingga menyebabkan beberapa data menjadi kurang akurat. Terjemahan yang akurat dipengaruhi oleh penggunaan padanan yang baik pada bahasa sasaran. Namun terdapat beberapa data yang kurang akurat yang disebabkan oleh pengurangan - pengurangan yang tidak seharusnya dan pengalihan isi pesan sehingga pesan tidak dapat tersampaikan dengan baik.

Terjemahan berterima diidentifikasi dengan penyesuaian terhadap kaidah yang berlaku dan diterima pada bahasa sasaran. Data yang kurang berterima cenderung disebabkan oleh penggunaan diksi dan kolokasi yang kurang tepat. Misalnya menggeliat 
tidak berterima untuk berkolokasi dengan kebutuhan. Beberapa data yang kurang berterima juga disebabkan oleh penyusunan kalimat yang tidak parallel dan terlalu kaku.

Pada terjemahan novel Fifty Shades of Grey dari 196 data ditemukan terjemahan akurat sebanyak 117 data $(59,7 \%)$, terjemahan kurang akurat sebanyak 66 data $(33,7 \%)$ dan terjemahan yang tidak akurat berjumlah 13 data (6,6\%). Sedangkan untuk aspek keberterimaan data yang berterima adalah sebanyak data yang berterima berjumlah 112 data $(57,1 \%)$ berdasarkan hasil tersebut terjemahan kalimat yang mengandung eufemisme tergolong kurang berterima berjumlah 74 data $(37,8 \%)$, dan tidak berterima sebanyak 10 data $(5,1 \%)$.

\section{SIMPULAN DAN SARAN}

\section{Simpulan}

Berdasarkan analisis terhadap data yang berupa eufemisme pada sexual organ dan sexual activity dalam novel Fifty Shades of Grey beserta terjemahannya, ditemukan bentuk eufemisme sebanyak 10 bentuk. Adapun kesepuluh bentuk eufemisme tersebut antara lain Hyperbole, figurative language, general for specific, understatement, circumlocution, jargon, flippancy, metaphor, colloquial, dan part for whole euphemism. Di dalam penelitian ini, bentuk eufemisme organ seksual yang paling banyak adalah umum-khusus sebanyak 33 data, sedangkan bentuk eufemisme pada aktifitas seksual didominasi oleh Hyperbole yaitu sebanyak 37 data.

Di dalam penelitian ini, ditemukan 13 macam teknik yang digunakan penerjemah dalam menerjemahkan kalimat yang mengandung eufemisme antara lain teknik kesepadanan lazim, amplifikasi, transposisi, reduksi, variasi, generalisasi, kompensasi, harfiah, kreasi diskursif, adaptasi, kompresi linguistik, peminjaman, dan teknik modulasi. Teknik penerjemahan yang paling banyak digunakan oleh penerjemah dalam menerjemahkan organ dan aktifitas seksual yang mengandung eufemisme adalah teknik kesepadanan lazim.

Dari 196 data yang merupakan organ dan aktifitas seksual yang mengandung eufemisme. Berdasarkan hasil persentase, data yang akurat sebanyak 59,7\%, data yang kurang akurat sebanyak 37,7\%, dan data yang tidak akurat sebanyak 6,6\%. Berdasarkan teknik yang digunakan, teknik padanan lazim, amplifikasi dan transposisi memberikan dampak yang baik terhadap keakuratan terjemahan kalimat yang 
mengandung eufemisme, sedangkan penggunaan teknik kreasi diskursif dan teknik reduksi memberikan dampak yang kurang baik terhadap terjemahan. Data yang kurang berterima biasanya dipengaruhi oleh penggunaan teknik kreasi diskursif yang mengubah isi pesan yang ada dan tidak sesuai dengan konteks yang ada. Dan beberapa data yang kurang berterima juga dipengaruhi oleh ungkapan yang tidak berkolokasi dengan ungkapan sebelumnya. Sehingga berdasarkan hasil diskusi yang dilakukan rater, terjemahan novel Fifty Shades of Grey cenderung dinilai kurang baik. Karena pesan yang terdapat dalam bahasa sumber kurang tersampaikan dengan baik dalam bahasa sasaran.

\section{Saran}

Setelah melakukan penelitian, peneliti berpendapat bahwa penerjemah novel Fifty Shades of Grey akan lebih baik apabila lebih memperhatikan kolokasi-kolokasi, padanan, dan memperhatikan susunan kalimat terjemahan agar terjemahan terasa lebih alami dan berterima yang tepat agar kalimat terasa lebih alamiah dan berterima dalam bahasa sasaran. Teknik reduksi sebaiknya dikurangi, karena jika mengurangi bagianbagian yang penting, pesan dalam basa sumber tidak akan tersampaikan dengan baik. Begitu pula dengan penggunaan teknik kreasi diskursif, karena penggunaan teknik ini sangat mempengaruhi tingkat keakuratan terjemahan.

Perlu dilakukan penelitian yang lebih lanjut mengenai novel- novel yang bertema dewasa, apakah beberapa novel dewasa tersebut juga banyak menggunakan eufemisme atau tidak sebagai perbandingan. Peneliti selanjutnya juga bisa melihat bagaimana tanggapan pembaca dengan penyajian novel dewasa yang menggunakan banyak eufemisme di dalamnya dan bagaimana tanggapan pembaca terhadap novel dewasa yang tidak menggunakan eufemisme. 


\section{DAFTAR PUSTAKA}

Abdurrahman \& Soejono. (1999). Metode penelitian: Suatu pemikiran dan penerapan. Jakarta: Rineka Cipta.

Allan, K., \& Burridge, K. (1991).Euphemism \& dysphemisun: Language used as shield and weapon. Oxford: Oxford University Press.

Chaer, A (1989). Pengantar Semantik Bahasa Indonesia. Jakarta.

Chaer, A.(1994). Linguistik umum. Jakarta: Rineka Cipta.

James, E. (2011). Fifty shades of grey. Waxahachin: The Writer's Coffee Shop.

Molina, L.,\&Albir, A.H. (2002). Translation technique and revisited: A dynamic and functional approach. Meta: Translator's journal,XLVII (4), 498-512.

Nababan, M.R. (2003). Teori menerjemah Bahasa Inggris. Yogyakarta: Pustaka Pelajar.

Nababan, M.R. (2008). Strategi penilaian kualitas terjemahan. Jurnal linguistik bahasa,II(1), 54-65.

Spradley, J.P. (1980). Metode etnografi. Yogyakarta: Tiara Wacana.

Sutopo, H. B. (2006). Penelitian kualitatif: Dasar teori dan terapannya dalam penelitian. Surakarta: Universitas Sebelas Maret. 